\title{
Citomegalovirose congênita: relato de caso
}

\author{
Congenital cytomegalovirus infection: a case report
}

Patrícia de Fátima Azevedo ${ }^{1}$, Alex Sandro Rolland de Souza ${ }^{2}$, Carlos Noronha Neto ${ }^{3}$, Marcelo Marques de Souza Lima ${ }^{4}$, Alexandre Silva Cardoso ${ }^{5}$, Ana Maria Feitosa Porto ${ }^{6}$

\section{RESUMO}

A citomegalovirose congênita sintomática é entidade clínica de grande importância devido a sua vasta sintomatologia fetal. No Brasil, o diagnóstico intra-útero é ainda pouco realizado, apesar do grande arsenal propedêutico. Relatamos um caso de citomegalovirose congênita grave com hepatoesplenomegalia, agenesia parcial do vérmix cerebelar, calcificações intracranianas, placentomegalia, aumento da ecogenicidade intestinal e renal, cardiomegalia, hipoplasia pulmonar, derrame pericárdico e ascite. A ressonância nuclear magnética fetal foi utilizada para confirmação dos achados ultra-sonográficos. A amniocentese foi realizada para análise do líquido amniótico por meio da PCR, sendo evidenciado resultado positivo. O óbito fetal foi constatado na $31^{\text {a }}$ semana de gestação, sendo confirmados os achados através da citopatologia e estudo anatomopatológico do natimorto. $\mathrm{O}$ arsenal propedêutico existente, na atualidade, para diagnóstico intra-útero da citomegalovirose congênita é de grande importância para confirmação diagnóstica e determinação do prognóstico fetal.

PALAVRAS-CHAVE: Citomegalovírus; Infecções por citomegalovirus/congênito; Diagnóstico pré-natal; Ultrasonografia pré-natal; Imagem por ressonância magnética

\section{ABSTRACT}

Congenital cytomegalovirus infection is an important clinical entity, due to its sonographic symptomatology. In Brazil, in utero diagnosis is not accomplished despite the improvements in diagnostic methods. We report a congenital infection including: splenomegaly and hepatomegaly, hypoplasia of the cerebellar vermis, intracranial calcifications, hyperechoic kidneys, hyperechoic bowel, cardiomegaly, lung hypoplasia, ascites, and pericardial effusion. Fetal magnetic resonance imaging confirmed the sonographic findings. Amniocentesis was performed for cytomegalovirus PCR in amniotic fluid, which confirmed fetal infection. Fetal loss occurred in the $31^{\text {st }}$ week of pregnancy. Necropsy studies confirmed the sonographic findings. The diagnostic methods have been useful to confirm congenital cytomegalovirus infection and to establish fetal outcome.

KEYWORDS: Cytomegalovirus; Cytomegalovirus infections/congenital; Prenatal diagnosis; Ultrasonography, prenatal; Magnetic resonance Imaging

\section{Introdução}

A citomegalovirose congênita ocupa lugar de destaque no cenário mundial acometendo cerca de 0,2 e 2,2\% dos recém-nascidos ${ }^{1,2}$. Enquanto em alguns países do primeiro mundo a incidência pode ser extremamente baixa, em torno de 0,9 por 1000 recém-nascidos ${ }^{3}$, no Brasil mostrou-se incidência de 0,5 a $6,8 \%{ }^{2,4,5}$, embora poucos estudos epidemiológicos tenham sido realizados.

Durante a gestação, a transmissão vertical do vírus pode ocorrer por passagem transplacentária, como resultado de infecção materna aguda ou por reativação de vírus endógeno. O citomegalovírus (CMV)

\footnotetext{
Centro de Atenção à Mulher - Setor de Medicina Fetal do Instituto Materno Infantil Prof. Fernando Figueira - SEMEFE -IMIP - Recife (PE) - Brasil. 1 Residente de Ultra-sonografia em Ginecologia e Obstetrícia do Instituto Materno Infantil Prof. Fernando Figueira - IMIP - Recife (PE) - Brasil.

2 Médico Ginecologista e Obstetra e Especialista em Medicina Fetal do Instituto Materno Infantil Prof. Fernando Figueira - IMIP - Recife (PE) - Brasil.

3 Residente de Ginecologia e Obstetrícia do Instituto Materno Infantil Prof. Fernando Figueira - IMIP - Recife (PE) - Brasil.

4 Pós-graduando em Obstetrícia pela Universidade Federal de São Paulo - UNIFESP - São Paulo (SP) - Brasil.

5 Residente de Medicina Fetal do Instituto Materno Infantil Prof. Fernando Figueira - IMIP - Recife (PE) - Brasil.

6 Coordenadora do Programa de Residência Médica em Ginecologia e Obstetrícia do Instituto Materno Infantil Prof. Fernando Figueira - IMIP-Recife (PE) - Brasil. Correspondência: Alex Sandro Rolland de Souza

Av. Rui Barbosa, 579, apto 406 - Graças - 52011-040 - Recife - PE - Telefone: (81) 3221-7924 - e-mail: alexrolland@uol.com.br

Recebido em: 17/3/2005

Aceito com modificações em: 19/12/2005
}

Rev Bras Ginecol Obstet. 2005; 27(12): 750-8 
é um herpesvirus humano que se caracteriza por apresentar latência, não é eliminado do organismo, permanecendo em seu interior, sendo possível reativações em diferentes circunstâncias, principalmente em casos de modificação da resposta imunológica, como: gestação, uso de drogas imunossupressoras, síndrome da imunodeficiência adquirida, entre outras ${ }^{2}$.

Em termos de prevalência, a citomegalovirose congênita é inversamente proporcional ao status socioeconômico $(83,5 \%$ em gestantes de nível socioeconômico baixo, contrastando com $49,3 \%$ na classe econômica elevada) ${ }^{1}$. Também se observa aumento da prevalência com a paridade e com a faixa etária ${ }^{1}$.

Calcula-se em $2,1 \%$ a incidência de infecção aguda na gestação. Nesses casos, o risco de contaminação fetal na primoinfecção varia entre $30-40 \%$, sendo o risco de 1 a 2,2\% na infecção recorrente $^{6}$. Cerca de $90 \%$ das crianças infectadas são assintomáticas ao nascimento e $10 \%$ dessas desenvolvem distúrbios neurossensoriais no decorrer de sua vida. Essas seqüelas são mais graves e de aparecimento mais precoce quando ocorrem na primoinfecção materna em relação às crianças infectadas devido à reativação. Aproximadamente $10 \%$ das crianças infectadas, ao nascimento, apresentarão sinais clínicos da infecção congênita por CMV: petéquias $(75 \%)$, hepatoesplenomegalia $(60 \%)$, icterícia com bilirrubina direta $>2 \mathrm{mg} / \mathrm{dL}$ e TGP $>80 \mathrm{UI} / \mathrm{mL}(80 \%)$, trombocitopenia $(77 \%)$, anemia, microcefalia, calcificações intracranianas e surdez neurossensorial $(50 \%)^{2,6}$.

O CMV pode ser transmitido ao feto ao longo de toda a gestação. Não há influência da idade gestacional no risco de transmissão intra-uterina, entretanto as conseqüências clínicas parecem se agravar quando a infecção ocorre antes da $20^{\mathrm{a}}$ semana de gestação ${ }^{7}$. Quando a infecção aguda ocorre no primeiro trimestre, o risco de seqüelas neurossensoriais é de $35-40 \%$; já no $2^{\circ}$ e $3^{\circ}$ trimestres, o risco varia de $8-25$ e $0-7 \%$, respectivamente $^{2}$.

Devido à alta incidência de infecção congênita por CMV e à possibilidade do desenvolvimento de seqüelas fetais irreversiveis durante a vida intra-uterina, há atualmente maior preocupação com o rastreamento e diagnóstico desta infecção na gravidez. Entretanto, ainda não há consenso na literatura sobre a recomendação do rastreamento universal no pré-natal da citomegalovirose congênita ${ }^{8}$. No Brasil esse rastreamento ainda não é recomendado, baseado na não-existência de imunidade permanente, em não haver uma terapia eficaz que possa ser utilizada durante a gestação e na possibilidade de gerar ansiedade desne- cessária nos pais e na equipe médica ${ }^{2,9}$. Entretanto, alguns estudos recomendam o rastreamento, justificado principalmente pela elevada incidência do $\mathrm{CMV}^{6,10}$.

O diagnóstico fetal é realizado por amniocentese, sendo a reação em cadeia de polimerase (PCR) o método de escolha ${ }^{2,6,11}$. Preconiza-se sua realização a partir de 21 semanas de gestação ${ }^{2}$. Esse método propedêutico é realizado no líquido amniótico, em decorrência de o epitélio tubular renal fetal apresentar-se como o local de maior replicação viral. A positividade do teste confirma a infecção fetal, mas não avalia a gravidade. Nesse aspecto, a ultra-sonografia fornece informações importantes a respeito do prognóstico fetal. As alterações ecográficas que podem alertar o obstetra incluem: restrição de crescimento intra-útero, hiperecogenicidade intestinal, dilatação moderada/grave dos ventrículos cerebrais, microcefalia, calcificações intracranianas, aumento da densidade placentária, hepatoesplenomegalia, ascite, oligoidrâmnio ou poliidrâmnio e eventualmente anasarca feto-placentáriaa, ${ }^{2,6,12}$.

A ressonância nuclear magnética durante o pré-natal ou no período neonatal pode ser utilizada como método complementar à ultrasonografia para melhor esclarecer o diagnóstico das alterações morfológicas fetais, oferecendo informações adicionais, principalmente as relativas ao sistema nervoso central ${ }^{6,13-15}$.

Até o momento, não há nenhum tratamento intra-útero para a citomegalovirose congêni$\mathrm{ta}^{16}$. Algum progresso tem sido atingido na prevenção da infecção, no entanto o tratamento para a doença estabelecida permanece dificil e em fase experimental. Na prática, o primeiro objetivo seria prevenir a infecção materna, por meio de medidas preventivas e de higiene, e/ou diminuir sua gravidade, uma vez que a vacinação ainda se encontra em estágio experimental; o segundo objetivo seria diminuir a taxa de transmissão materno-fetal com uso profilático de agentes antivirais; e o terceiro, diminuir a gravidade da infecção pelo tratamento intra-útero dos conceptos infectados. Sendo assim, atualmente, tem sido considerado que o desenvolvimento de vacinas contra o CMV é problema de saúde pública, devendo-se estimular pesquisas nessa área e também no desenvolvimento de terapias antivirais para prevenir sintomas dos recémnascidos infectados ${ }^{17}$. O desenvolvimento de uma droga sem riscos para a mãe, com concentração adequada na placenta, no líquido amniótico ou até mesmo no sangue fetal, seria o desejável, pois permitiria reduzir, em proporção importante, a carga viral no compartimento feto-anexial. Os 
recém-nascidos com evidência de comprometimento do sistema nervoso central têm recebido tratamento com ganciclovir ${ }^{18}$; no entanto, esta droga apresenta pouca biodisponibilidade oral e elevada toxicidade, não devendo ser usada durante a gestação, devido ao seu alto potencial teratogênico.

Todos estes fatores demonstram a importância e a complexidade do estudo da citomegalovirose congênita. É importante obter informações sobre a eficácia dos métodos diagnósticos, fontes de contaminação materna, avaliação do risco fetal e a incidência de sintomas, bem como métodos profiláticos e terapêuticos.

\section{Relato do Caso}

Todas as informações foram obtidas após consentimento informado da paciente, aprovação pela Comissão de Ética em Pesquisa do Instituto Materno Infantil Prof. Fernando Figueira (IMIP), seguindo as orientações do Código de Ética Médica - Resolução do Conselho Federal de Medicina 1246/1998 e observados os Principios Éticos para Pesquisa Médica Envolvendo Indivíduos Humanos descritos na Declaração de Helsinki (1964) e atualizada pela 52a Assembléia Geral da Associação Médica Mundial em Edimburgo (2000).

M.L.L., 26 anos, gesta I, para 0, foi admitida no setor de medicina fetal da enfermaria de alto risco do IMIP em 22 de outubro de 2003 com 26 semanas e 6 dias (idade gestacional por ultrasonografia do segundo trimestre), data da última menstruação desconhecida, portando exame ultrasonográfico com diagnóstico de oligoidrâmnio e múltiplas malformações fetais.

Relatava quadro de diarréia aguda por volta do $3^{\circ} / 4^{\circ}$ mês de gestação, sendo internada por 4 dias.

O exame físico geral na admissão não detectou anormalidades, verificando-se pressão arterial de 110/70 mmHg. Ao exame obstétrico, observou-se útero de tônus normal, sem dinâmica, com $27 \mathrm{~cm}$ de altura. Feto em situação longitudinal, apresentação cefálica com batimentos cardíacos de $144 \mathrm{bpm}$. Toque vaginal apresentando colo uterino fechado.

As hipóteses diagnósticas, no ato do internamento, foram de gestação única tópica de 26 semanas e 6 dias, ultra-sonografia e malformação fetal a esclarecer.
No mesmo dia de internação hospitalar, submeteu-se a ultra-sonografia morfológica, na qual ficaram evidenciados: agenesia parcial de vérmix cerebelar (Figura 1), derrame pericárdico (Figura 2), sinais de insuficiência cardiaca, hepatoesplenomegalia importante (Figura 3), ascite fetal leve (Figura 4), hiperecogenicidade de alças intestinais (Figuras 3 e 4) e aumento da ecogenicidade dos rins bilateralmente (Figura 5).

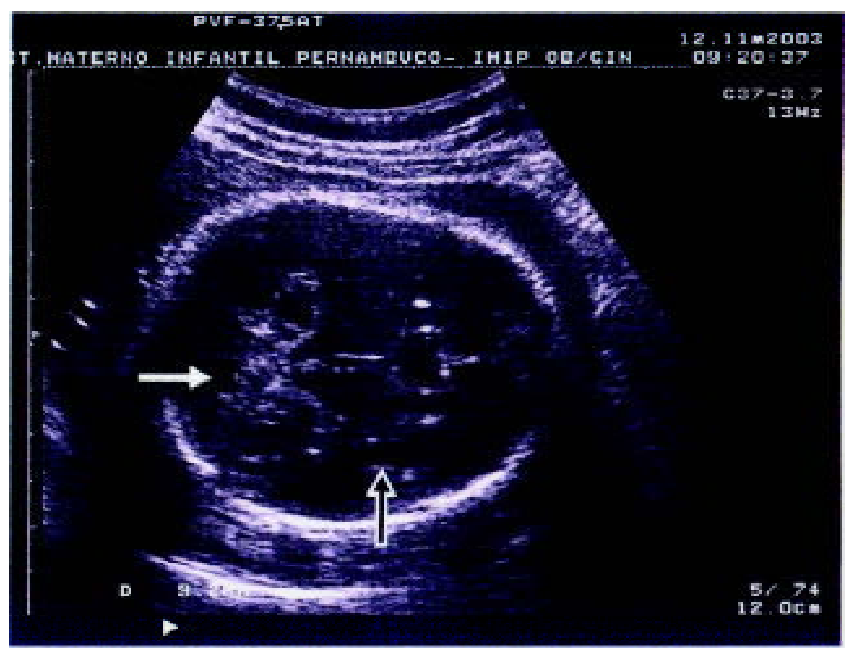

Figura 1 - Ultra-sonografia no plano transverso do pólo cefálico fetal apresentando imagem anecogênica na fossa posterior demonstrando agenesia parcial de vérmix cerebelar (seta cheia) e presença de imagens hiperecogênicas periventriculares (seta vazia).

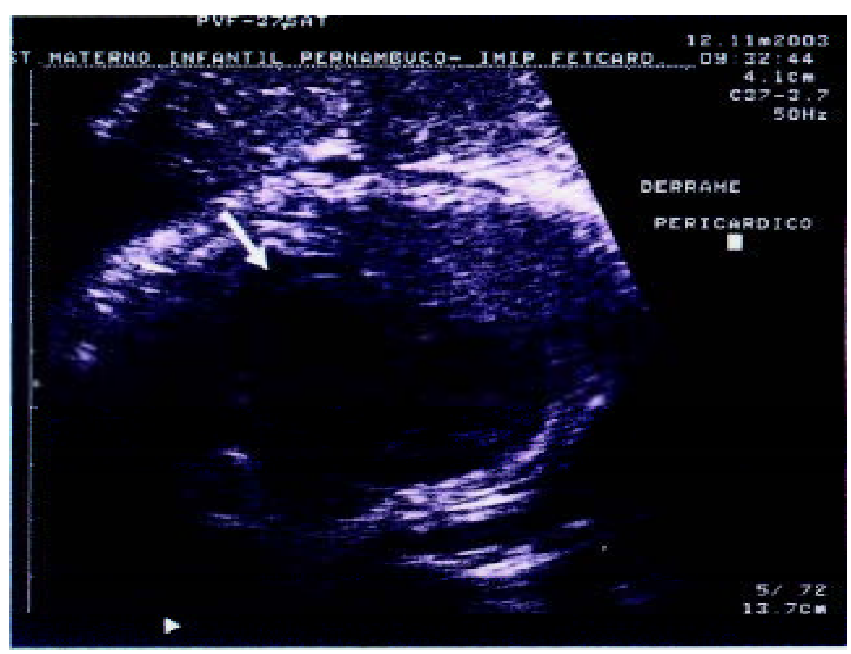

Figura 2 - Ultra-sonografia no plano transverso do tórax fetal apresentando aumento da área cardiaca com imagem anecogênica sugerindo derrame pericárdico. 

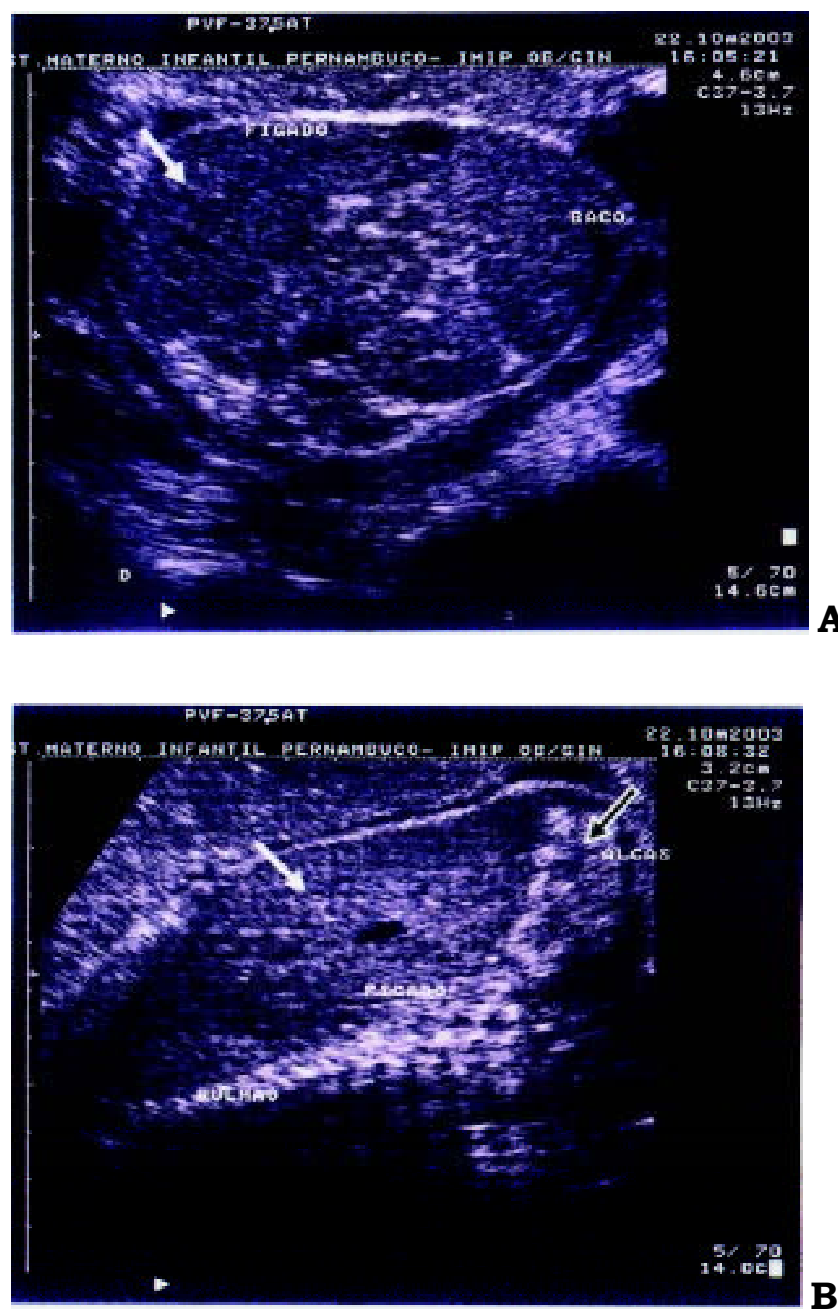

Figura 3 - Ultra-sonografia do abdome fetal apresentando aumento do volume hepático (seta cheia) e aumento da ecogenicidade das alças intestinais (seta vazia). A - plano transverso. B - plano longitudinal.

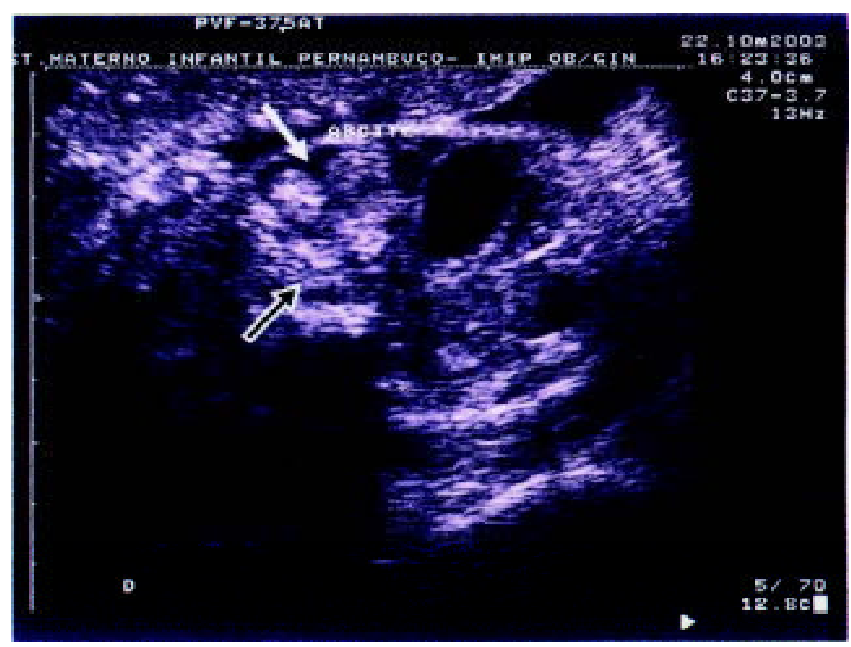

Figura 4 - Ultra-sonografia no plano transverso da pelve fetal apresentando aumento da ecogenicidade das alças intestinais (seta vazia) envolta por imagem anecogênica (seta cheia) demonstrando ascite.

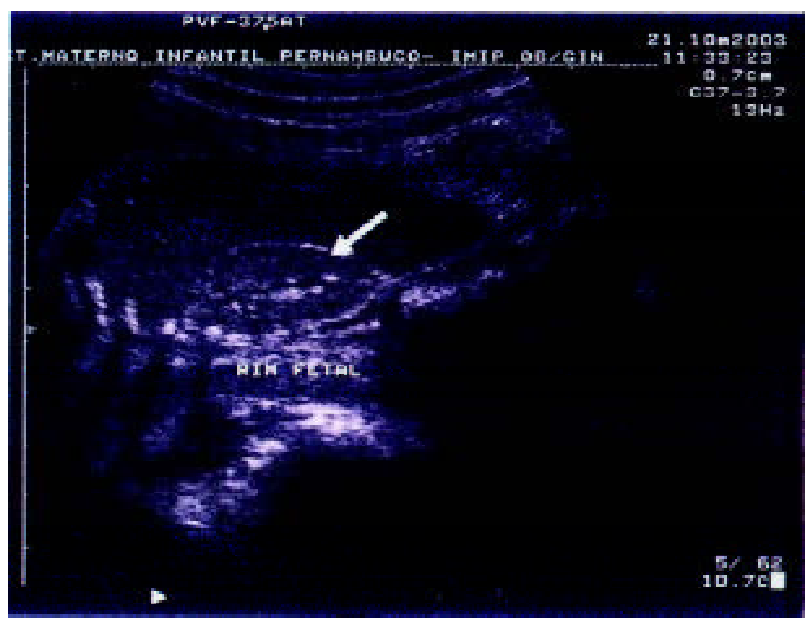

Figura 5 - Ultra-sonografia no plano longitudinal dos rins fetais apresentando aumento de sua ecogenicidade.

Foram realizados exames de rotina, além das sorologias maternas, ecocardiografia fetal e ressonância nuclear magnética. Foram demonstrados hemoglobina de 10,8 g\%, hematócrito de 33,7\% e leucograma normal. O sumário de urina e o teste de tolerância à glicose simplificado (50 g de dextrosol) foram normais. A classificação sanguínea era "A", fator Rh positivo, sorologia para HIV negativa e VDRL não reagente. As sorologias maternas revelaram IgG positiva e IgM negativa para toxoplasmose e rubéola, sendo IgG e IgM positivas para citomegalovírus.

A ecocardiografia fetal evidenciou dilatação leve de câmaras cardíacas direitas, contratilidade miocárdica preservada, presença de refluxo tricúspide leve, holossistólico, e refluxo pulmonar, não sendo possivel boa definição da bifurcação do tronco pulmonar e do fluxo do canal nesta avaliação inicial, as quais foram estabelecidas como normais, posteriormente.

A ressonância nuclear magnética fetal (Figuras 6 a 8) revelou sinais de hepatoesplenomegalia importante e ascite fetal, além de hidronefrose materna à direita moderada.

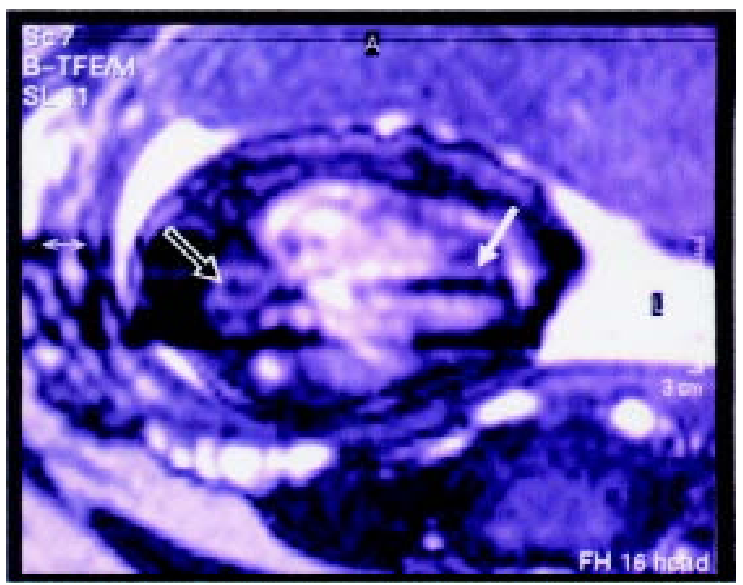

Figura 6 - Imagem em T2 de ressonância magnética no plano transverso do tórax fetal apresentando aumento do volume cardíaco (seta cheia) e pulmões de dimensões reduzidas (seta vazia). 

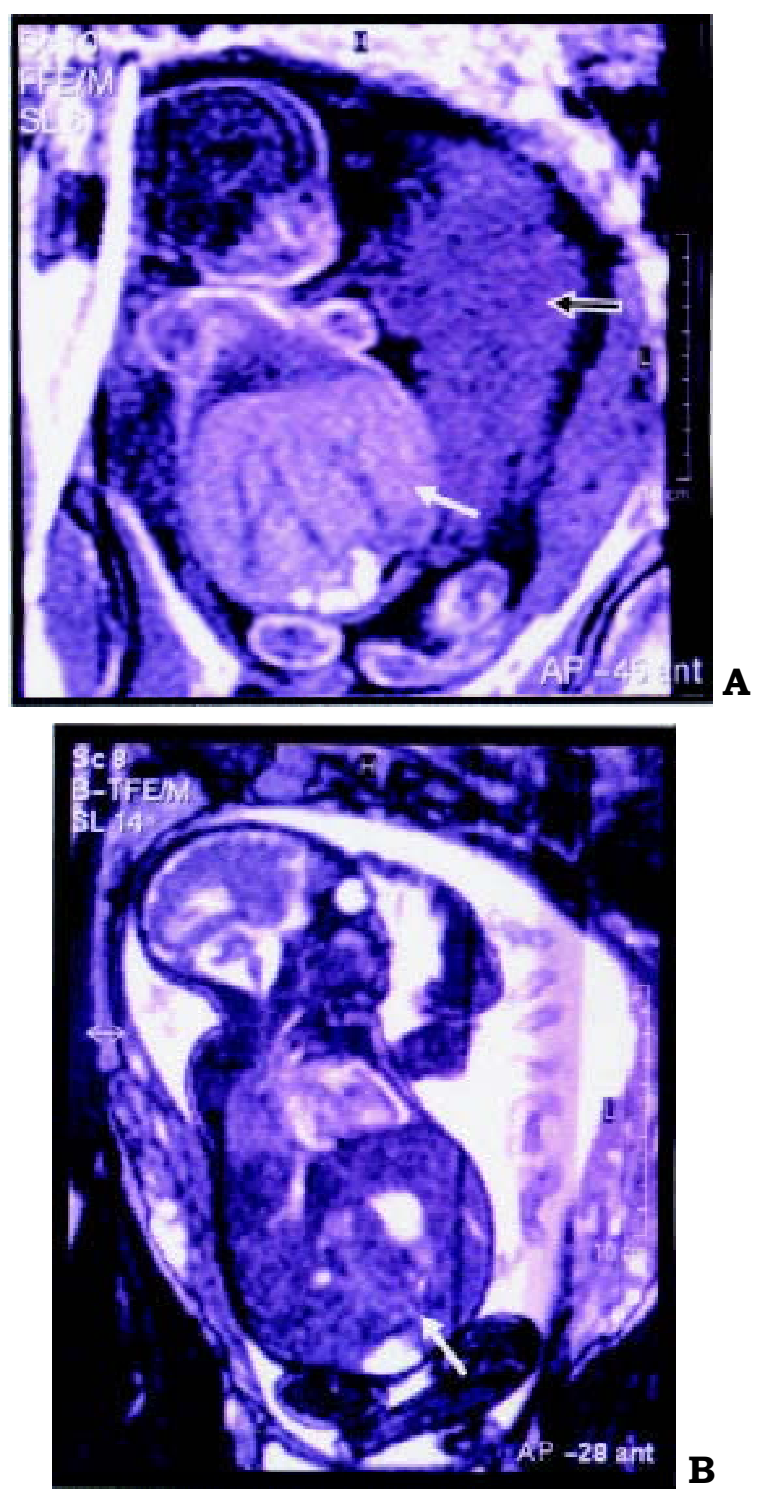

Figura 7 - Ressonância magnética no plano longitudinal do feto apresentando aumento do volume abdominal devido a hepatoesplenomegalia. Observe a presença de placentomegalia. A - imagem em T1. B - imagem em T2.

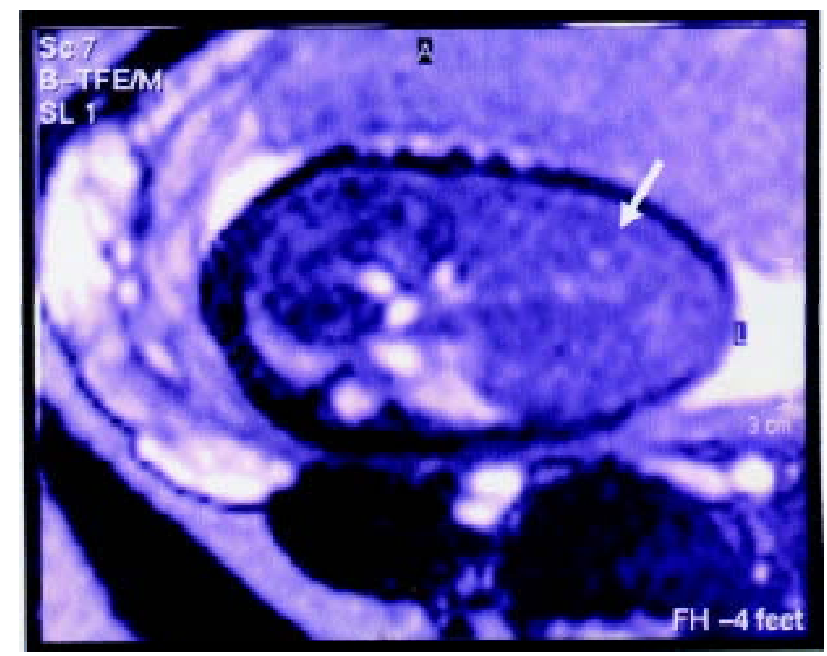

Figura 8 - Imagem em T2 de ressonância magnética no plano transverso do abdome fetal apresentando hepatoesplenomegalia. Observe a correspondência com a foto da ultra-sonografia (Figura 3).
Em 12 de novembro de 2003 foi submetida a nova ultra-sonografia morfológica, demonstrandose idade gestacional compativel com 29 semanas e 6 dias, líquido amniótico diminuído (indice de líquido amniótico de $6,0 \mathrm{~cm}$ ), placentomegalia com sinais de placentite, hepatoesplenomegalia grave (Figura 3), derrame pericárdico (Figura 2), ascite fetal leve (Figura 4), hiperecogenicidade de alças intestinais (Figuras 3 e 4) e aumento da ecogenicidade dos rins (Figura 5).

Diante de tais achados, associados aos resultados dos exames e das sorologias maternas, foi realizada a PCR no líquido amniótico, por meio da amniocentese, para diagnóstico de citomegalovirose congênita, em 13 de novembro de 2003, na $30^{a}$ semana de gestação, cujo resultado se revelou positivo.

O último estudo dopplervelocimétrico em 14 de novembro de 2003 não evidenciou comprometimento da vitalidade fetal e optou-se pela corticosteroidoterapia, para aceleração da maturidade pulmonar fetal, com betametasona, TM, $12 \mathrm{mg}, 2$ doses com intervalo de 24 horas, sendo constatado o óbito fetal, pela ultra-sonografia de controle, com 31 semanas e 3 dias de idade gestacional.

Foi submetida à indução do trabalho de parto com ocitocina após preparo de colo com misoprostol. Evoluiu para parto transpelviano com um natimorto do sexo feminino, pesando $1.980 \mathrm{~g}$. A genitora recebeu alta hospitalar após 24 horas do parto, sem intercorrências clínico-obstétricas, tendo consentido com o estudo anatomopatológico do natimorto e placenta.

O estudo anatomopatológico revelou: feto macerado com destacamento da epiderme e hiperemia, abdome globoso com petéquias em tronco e membros; realizada a abertura do tórax e do abdome, com incisão mediana, observaram-se hemoperitôneo, hepatoesplenomegalia e alterações hemorrágicas em alças intestinais; proporção coração/pulmões sugerindo hipoplasia pulmonar, sendo observadas petéquias nas bases pulmonares; à abertura bimastoidea com rebatimento do couro cabeludo foi encontrada hemorragia difusa subgaleal e cerebral.

A citopatologia hepática observou epitélio dos ductos biliares contendo células de inclusão nuclear citomegálicas, citoplasmas eosinofílicos e núcleos hipercromáticos (Figura 9); nos pulmões foram observadas células de inclusão citomegálicas no epitélio dos brônquios (Figura 10A) e rins contendo células de inclusão no epitélio tubular proximal (Figura 10B). 


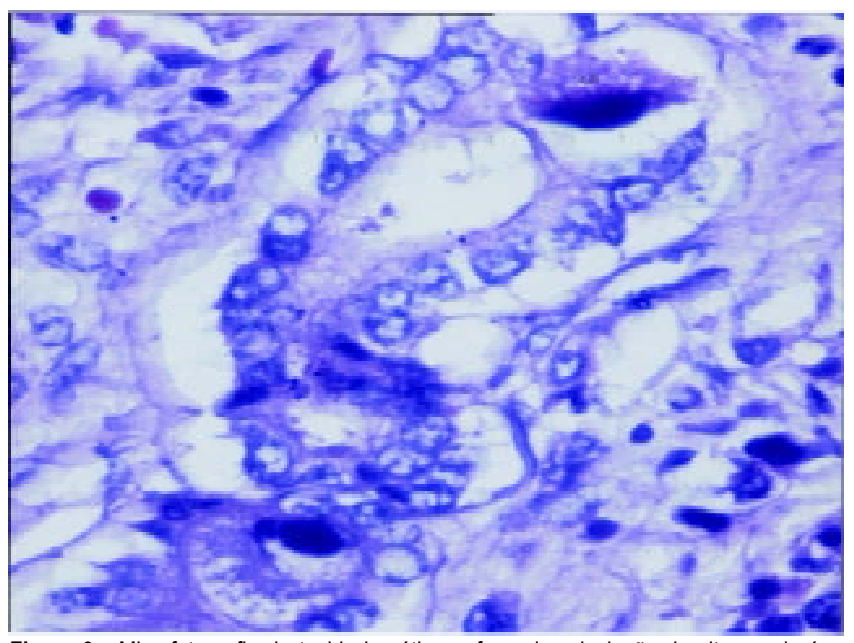

Figura 9 - Microfotografia de tecido hepático enfocando a inclusão do citomegalovírus no epitélio de ductos biliares e inflamação crônica do parênquima (HE 400X).

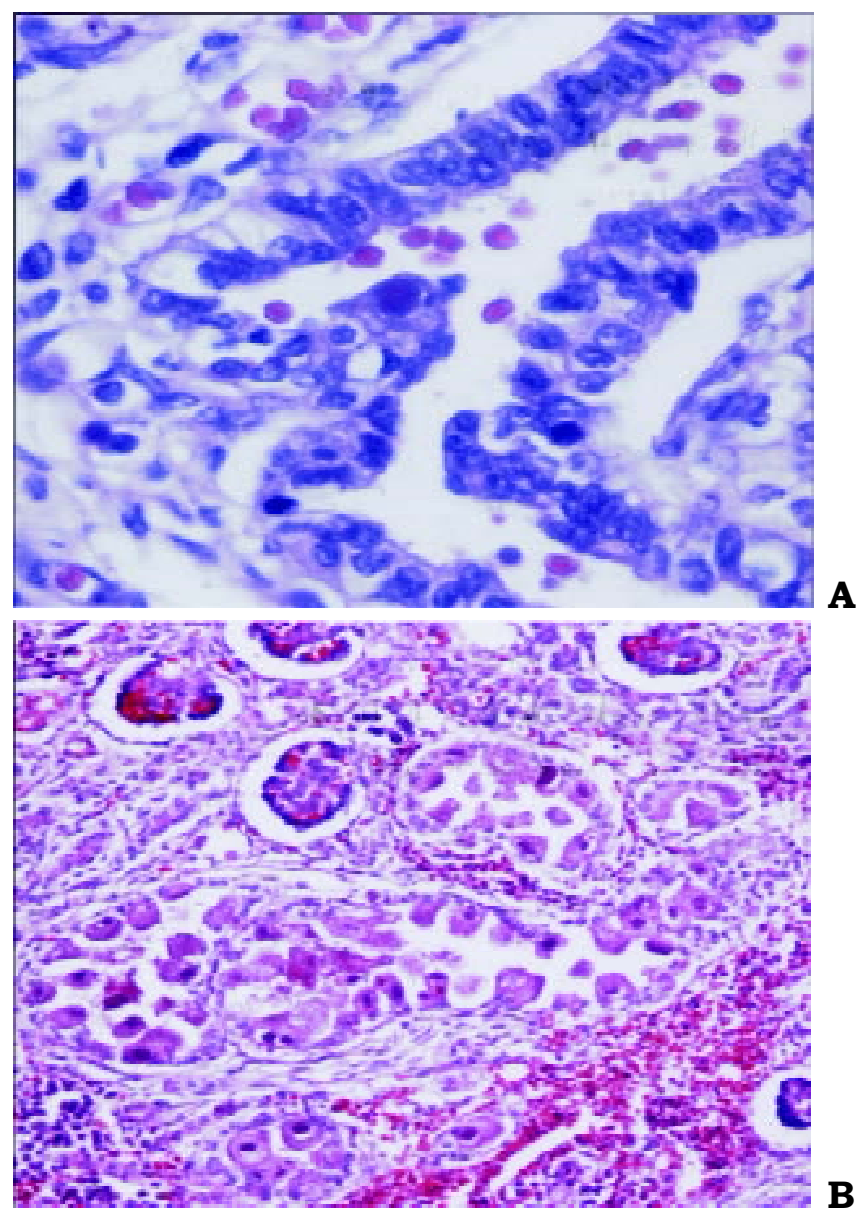

Figura 10 - Histologia do pulmão em $(A)$ e rim em $(B)$ - presença de células de inclusão citomegálica com núcleo hipercromático.

\section{Discussão}

Nos países desenvolvidos cerca de 3\% dos recém-nascidos apresentam retardo mental e aproximadamente $10 \%$ desses casos são atribuídos às doenças infecciosas ${ }^{19}$; entre elas, a cito- megalovirose congênita ocupa lugar de destaque. Apenas 5 a 20\% das infecções congênitas pelo CMV são sintomáticas ao nascimento, podendo apresentar hepatoesplenomegalia, microcefalia, recémnascidos pequenos para a idade gestacional, entre outros sintomas.

No Brasil, estudos têm mostrado que a prevalência de anticorpos IgG anti-CMV em gestantes varia de 66,5 a $92 \%{ }^{5}$. Nos países em desenvolvimento, a imunidade contra o CMV é adquirida principalmente na infância. A promiscuidade e o aleitamento materno possuem papel importante na imunização dessas populações e a transmissão viral ocorre principalmente por via oral e respiratória. Os novos hábitos de vida impostos pela sociedade também contribuem para o aumento da prevalência da infecção. Grande parte das mulheres trabalha fora de casa, resultando em maior número de crianças em creches e escolas de tempo integral. Evidências sugerem que entre 25 e $80 \%$ dessas crianças adquirem a infecção nesses locais e permanecem excretando o virus na saliva e urina por período prolongado ( $>2$ anos), podendo transmiti-los a suas mães.

Atualmente, no Brasil não se recomenda o rastreamento universal do CMV em gestantes. Entretanto, grupos de riscos podem se beneficiar desta medida profilática, como: enfermeiras, médicas, trabalhadoras de creches, escolas infantis, unidades de diálise, de saúde mental e aquelas que convivem com imunodeprimidos ${ }^{2,9}$, sendo prudente a avaliação sorológica inicial destas pacientes, determinando o seu perfil sorológico. Desta forma, em caso de suspeita de infecção fetal durante a gestação, poder-se-á avaliar a gravidade da doença fetal, além do que o rastreamento pode diminuir a incidência de infecção aguda, uma vez que gestantes soronegativas poderiam se beneficiar de medidas profiláticas e de higiene, permitindo o diagnóstico precoce da doença congênita e adotando cuidados especiais aos recém-nascidos infectados com a finalidade de impedir a disseminação do vírus.

Anticorpos IgM podem ser produzidos durante os episódios de reativação por período de até 6 a 9 meses $^{20,21}$. Desta forma, caso não se saiba o perfil sorológico da paciente fica dificil diagnosticar o momento da infecção, se recente ou recorrente, já que a transmissão do vírus ao feto ocorre como resultado da infecção materna aguda ou por reativação de vírus endógeno. Entretanto, sintomas fetais graves são observados mais freqüentemente na primoinfecção materna ${ }^{12}$. Apesar de esta paciente não dispor de sorologia pré-concepcional, diante da riqueza da sintomatologia dos vários sistemas orgânicos acometidos podemos pensar que 
esta infecção possa ter ocorrido no início da gestação e como resultado de uma primoinfecção materna. Ainda podemos acrescentar o fato de a gestante ter apresentado quadro de infecção inespecífica (diarréia aguda com internamento hospitalar) no início da gestação, sugerindo o início da doença materna.

Apesar de estudos epidemiológicos prévios sugerirem que os anticorpos maternos não diminuem a incidência da infecção intra-uterina ou perinatal, os mesmos possivelmente protegem contra infecção maciça com acometimento e dano sistêmico grave.

A contaminação fetal acontece no mínimo de 2 a 3 semanas após a viremia materna, mas pode ser retardada em casos de transmissão por via ascendente. A viremia fetal pode ocorrer várias semanas depois da primoinfecção materna e este atraso seria fator de bom prognóstico fetal: uma passagem tardia do vírus após a produção de anticorpos maternos diminuiria o risco de lesão cerebral. Da mesma forma, a demora da resposta imunitária do feto (e recém-nascido) poderá também agravar a situação ${ }^{12}$.

Ao atingir o feto, o vírus aloja-se predominantemente no epitélio tubular renal, onde inicia sua replicação. Como conseqüência, ocorre excreção do CMV por via urinária, fazendo com que o líquido amniótico reflita a carga viral na urina fetal. Além disso, o líquido amniótico é ingerido pelo feto, permitindo que o virus se instale e replique na orofaringe, atingindo a circulação fetal e lesando outros órgãos. Foi observado o acometimento renal por meio da ultra-sonografia, com aumento da ecogenicidade renal, e confirmado pela histologia, com presença de células de inclusão citomegálica no epitélio tubular.

Outros métodos de diagnóstico materno podem ser utilizados, como o teste de avidez, que significa afinidade do anticorpo pelo antígeno: a presença de baixa avidez $(<30 \%)$ caracteriza infecção recente ( $<3$ meses) e alta avidez $(>50 \%)$, infecção antiga. Desta forma, sua utilidade se aplica quando existe a suspeita de infecção no início da gestação ${ }^{22}$. A determinação da viremia materna tem recebido pouca importância devido à dificuldade de isolamento do vírus. A técnica de PCR (genoma de CMV por biologia molecular) representa o meio diagnóstico mais utilizado atualmente na prática ${ }^{11,12}$.

O diagnóstico fetal de escolha é pela amniocentese para coleta do líquido amniótico e realização da $\mathrm{PCR}^{2,6,11}$, já que o epitélio tubular renal é o local de maior replicação viral. Tem sido preconizada sua realização na $21^{\text {a }}$ semana de gravi$\mathrm{dez}^{2,20}$. Neste caso, a amniocentese diagnóstica foi realizada com 30 semanas de gestação, corroborando a literatura.

A ultra-sonografia merece destaque quanto às informações que pode nos fornecer a respeito da gravidade da lesão fetal. Diante dos vários achados ultra-sonográficos encontrados nesta paciente, como: hepatoesplenomegalia, calcificações intracranianas, aumento da ecogenicidade dos rins, placentomegalia (placentite), suspeita de agenesia de vérmix cerebelar, líquido amniótico diminuído, hiperecogenicidade de alças intestinais, ascite leve e derrame pericárdico, pode-se sugerir prognóstico bastante reservado. A ressonância nuclear magnética fetal, utilizada como método complementar à ultra-sonografia, revelou sinais de hepatoesplenomegalia importante e ascite fetal, além de hidronefrose materna à direita moderada.

A cordocentese pode ser utilizada na avaliação do prognóstico fetal pela coleta de sangue para análise bioquímica e hematológica (alterações das enzimas hepáticas, anemia e trombocitopenia). Diante dos achados ultra-sonográficos, decidiu-se pela não-realização da cordocentese, já que o prognóstico fetal era reservado. A determinação da carga viral no líquido amniótico parece ser o mais promissor quanto à avaliação do prognóstico fetal. Uma carga viral maior ou igual a $10^{5}$ cópias $/ \mathrm{mL}$ demonstra o desenvolvimento de doença sintomática no recém-nascido em todos os casos ${ }^{23}$.

Embora a história natural da infecção intrauterina pelo CMV não seja totalmente compreendida, sabe-se que alguns fetos são lesados de forma irreversivel. Essas crianças não apresentam benefício com a terapia pós-natal, no entanto se os fetos infectados pudessem ser detectados antes que este estado irreversivel ocorresse, o tratamento intra-uterino poderia apresentar algum benefício no curso da doença. Até o momento, não há nenhum tratamento intra-uterino para a infecção congênita pelo CMV.

Como o rastreamento sorológico para CMV não faz parte da rotina pré-natal no Brasil e também em nosso serviço, a grande maioria dos casos de infecção por CMV é suspeitada pela presença de alterações ecográficas fetais observadas durante o pré-natal ${ }^{12}$. Embora o exame ultrasonográfico morfológico normal possa fornecer certa segurança aos pais, não é capaz de predizer a evolução natural da doença intra-útero ou mesmo pós-natal.

O tratamento tem alguns objetivos: primeiro, visa prevenir a infecção materna e/ou diminuir sua gravidade. Tal fato poderia ser conseguido por meio de vacinação eficaz, contudo ainda em estágio experimental. Desta forma, deve-se investir nas medidas preventivas e de higiene que re- 
duzem a primoinfecção. A segunda meta seria diminuir a transmissão vertical, de dificil realização, já que existe grande dificuldade para o diagnóstico da infecção materna, devido à maioria dos casos serem assintomáticos ou pauci-sintomáticos, além da dificuldade na realização das sorologias maternas. Este argumento fundamenta-se no fato de que quatro a seis semanas são necessárias para a contaminação fetal e replicação antes de sua excreção no líquido amniótico. Então, se o tratamento for administrado imediatamente depois da soroconversão, poder-seia diminuir a viremia materna e possivelmente a freqüência e a gravidade da infecção fetal. Finalmente, o terceiro obejtivo seria diminuir a gravidade da infecção fetal pelo tratamento intra-útero dos fetos infectados. O desenvolvimento de uma droga sem perigo para mãe, com concentração adequada na placenta e líquido amniótico ou até mesmo no sangue fetal, permitiria reduzir em proporção importante a carga viral nos compartimentos feto-anexiais. Os agentes antivirais aprovados para uso no tratamento da infecção por CMV estão longe do ideal em termos de índice terapêutico, facilidade de administração e toxicidade. Nenhum agente antiviral foi aprovado para o tratamento intra-útero da infecção congênita por CMV, contudo nos recém-nascidos sintomáticos com a forma neonatal clínica têm-se administrado o ganciclovir, valganciclovir, foscarnet e cidofovir ${ }^{18}$.

Recentemente, alguns estudos vêm sugerindo melhores resultados com a utilização do ganciclovir para tratamento da infecção congênita neonatal, limitando o dano ao sistema nervoso central, particularmente a perda auditiva, que tem sido menor nos pacientes tratados com o ganciclovir ${ }^{18,24}$.

No Japão, foi administrada imunoglobulina hiperimune anti-CMV no abdome de um feto infectado diagnosticado com 26 semanas de gestação. Os exames fetais após o nascimento demonstraram niveis elevados de IgG e cultura de urina positiva. A PCR do líquido ascítico era negativa $^{25}$. Outro estudo, administrando imunoglobulina hiperimune, por via endovenosa, mensalmente às gestantes com primoinfecção por CMV, encontrou redução significante da incidência de infecção neonatal, quando comparada às gestantes que não receberam a terapia ${ }^{16}$.

Diferentes tipos de vacinas (imunização ativa) têm sido estudadas em humanos e em experimentos animais, algumas com resultados satisfatórios, evidenciando diminuição da mortalidade fetal e da infecção congênita por CMV. Desta forma, centros de estudos especializados estão recomendando prioridade em estudos para desen- volvimento de vacinas contra o $\mathrm{CMV}^{24}$.

Algum progresso tem sido atingido para a prevenção da infecção por CMV, no entanto o tratamento para a doença permanece dificil e em fase experimental. Na prática, a primeira medida seria trabalhar na prevenção da transmissão, na identificação de mães soronegativas e na difusão de conselhos de higiene e prevenção.

\section{Referências}

1. Stagno S, Pass RF, Cloud G, Britt WJ, Henderson RE, Walton PD, et al. Primary cytomegalovirus infection in pregnancy. Incidence, transmission to fetus and clinical outcome. JAMA. 1986;256(14):1904-8.

2. Couto JCF, Rodrigues MV, Melo GEBA, Menezes GA, Leite JM. Citomegalovírus e gestação: um antigo problema sem novas soluções. Femina. 2003;31(6):509-16.

3. Gaytant MA, Galama JM, Semmekrot BA, Melchers WJ, Sporken JM, Oosterbaan HP, et al. The incidence of congenital cytomegalovirus infections in the Netherlands. J Med Virol. 2005;76(1):71-5.

4. Pannuti CS, Vilas-Boas LS, Angelo MJ, Carvalho RP, Segre CM. Congenital cytomegalovirus infection. Occurrence in two socioeconomically distinct populations of a developing country. Rev Inst Med Trop São Paulo. 1985;27(2):105-7.

5. Santos DV, Souza MM, Gonçalves SH, Cotta AC, Melo LA, Andrade GM, et al. Congenital cytomegalovirus infection in a neonatal intensive care unit in Brazil evaluated by PCR and association with perinatal aspects. Rev Inst Med Trop São Paulo. 2000;42(3):129-32.

6. Brandão RS, Guerzet EA, Souza E, Camano L. Citomegalovírus: diagnóstico e conduta na infecção fetal. Femina. 2003;31(6):551-4.

7. Azam AZ, Vial Y, Fawer CL, Zufferey J, Hohlfeld P. Prenatal diagnosis of congenital cytomegalovirus infection. Obstet Gynecol. 2001;97(3):443-8.

8. Collinet P, Subtil D, Houfflin-Debarge V, Kacet N, Dewilde A, Puech F. Routine CMV screening during pregnancy. Eur J Obstet Gynecol Reprod Biol. 2004;114(1):3-11.

9. Brasil. Ministério da Saúde. Pré-natal e puerpério: atenção qualificada e humanizada - manual técnico. Brasília: Ministério da Saúde; 2005. p. 40-8.

10. Schlesinger Y, Reich D, Eidelman AI, Schimmel MS, Hassanin J, Miron D. Congenital cytomegalovirus infection in Israel: screening in different subpopulations. Isr Med Assoc J. 2005;7(4):237-40.

11. Gouarin S, Palmer P, Cointe D, Rogez S, Vabret A, Rozenberg F, et al. Congenital HCMV infection: a 
collaborative and comparative study of virus detection in amniotic fluid by culture and by PCR. J Clin Virol. 2001;21(1):47-55.

12. Jachemard F, Daffos F. Prise en charge des infections materno-foetales à cytomégalovirus. Paris: Service de Médicine Foetale/Institut de Puériculture de Paris; 2002.

13. de Vries LS, Gunardi H, Barth PG, Bok LA, VerboonMaciolek MA, Groenendaal F. The spectrum of cranial ultrasound and magnetic resonance imaging abnormalities in congenital cytomegalovirus infection. Neuropediatrics. 2004;35(2):113-9.

14. Stoisa D, De Luca SE, Florenzano NV, Mondello EJ, Eyheremendy E, Heinen F, et al. Utilidad de la RM ultra-rápida en el diagnóstico de la patología fetal. Rev Argent Radiol. 2003;67(4):393-403.

15. Massoc LP, Molho M. Utilidad de la resonancia magnética cerebral fetal en antenatal: como método de exploración complementario a la ultrasonografia. Rev Chil Ultrason. 2003;6(2):36-42.

16. Nigro G, Adler SP, La Torre R, Best AM; Congenital Cytomegalovirus Collaborating Group. Passive immunization during pregnancy for congenital cytomegalovirus infection. $N$ Engl $\mathrm{J}$ Med. 2005;353(13):1350-62.

17. Burny W, Liesnard C, Donner C, Marchant A. Epidemiology, pathogenesis and prevention of congenital cytomegalovirus infection. Expert Rev Anti Infect Ther. 2004;2(6):881-94.
18. Schleiss MR. Antiviral therapy of congenital cytomegalovirus infection. Semin Pediatr Infect Dis. 2005;16(1):50-9.

19. Gabbe M. Normal and problem pregnancies. 4th ed. New York: Churchill Livingstone; 2002. p. 301-32.

20. Lazzarotto T, Varani S, Guerra B, Nicolosi A, Lanari M, Landini MP. Prenatal indicators of congenital cytomegalovirus infection. J Pediatr. 2000;137(1):90-5.

21. Bodéus M, Beulné D, Goubau P. Ability of three IgG-avidity assays to exclude recent cytomegalovirus infection. Eur $J$ Clin Microbiol Infect Dis. $2001 ; 20(4): 248-52$.

22. Lazzarotto T, Gabrielli L, Lanari M, Guerra B, Bellucci $\mathrm{T}$, Sassi M, et al. Congenital cytomegalovirus infection: recent advances in the diagnosis of maternal infection. Hum Immunol. 2004;65(5):410-5.

23. Guerra B, Lazzarotto T, Quarta S, Lanari M, Bovicelli L, Nicolosi A, et al. Prenatal diagnosis of symptomatic congenital cytomegalovirus infection. Am J Obstet Gynecol. 2000;183(2):476-82.

24. Griffiths PD, Walter S. Cytomegalovirus. Curr Opin Infect Dis. 2005;18(3):241-5.

25. Negishi H, Yamada H, Hirayama E, Okuyama K, Sagawa $\mathrm{T}$, Matsumoto $\mathrm{Y}$, et al. Intraperitoneal administration of cytomegalovirus hyperimmunoglobulin to the cytomegalovirus-infected fetus. J Perinatol. 1998;18(6 Pt 1):466-9. 